\title{
El turismo en televisión: el caso de Buscamundos. Viajes por la vida
}

\section{Giovanna Mapelli ${ }^{i}$}

Università degli Studi di Milano (Italia)

\begin{abstract}
Resumen: El turismo alternativo aboga por el desarrollo de las comunidades más necesitadas, respetando el medioambiente y la cultura local. A partir de esta concepción, nace el programa televisivo Buscamundos. Viajes por la vida, que muestra los aspectos incluso más duros de los destinos de sus viajes y pone en primer plano el contacto con la población autóctona. El propósito del presente trabajo es analizar los rasgos lingüísticos de este programa, destacando las innovaciones que aporta a la lengua del turismo. El estudio se centrará en la primera entrega, dedicada a Haití, analizando el contenido y las estrategias comunicativas, verbales y visuales, empleadas para perfilar el rostro de este destino y para promocionar esta modalidad de turismo. Asimismo, se estudiará la página web del programa y su página en Facebook.
\end{abstract}

Palabras clave: turismo solidario, reportaje de viaje, documental de viaje, comunicación turística

Title: Tourism in television: the case of Buscamundos. Viajes por la vida

\begin{abstract}
The alternative tourism defends the development of the most needy communities, respecting the environment and the local culture. From this conception, the television program Buscamundos. Viajes por la vida borns. It shows the hardest aspects of travel destinations and emphasizes the contact with native population. The aim of this paper is to analyze the linguistic features of this program, stressing the innovations provided to the language of tourism. In particular, it focuses on the first episode, dedicated to Haiti and it analyzes the content and the communicative strategies, verbal and visual, used to outline this destination and to promoting this modality of tourism. Likewise, it will study the website of the program and its page on Facebook.
\end{abstract}

Keywords: solidarity tourism, travel report, travel documentary, tourism communication 


\section{Introducción}

Al lado del turismo tradicional, en el que la relación entre el viajero y la comunidad local es prácticamente nula, limitándose, en la mayoría de las ocasiones, a pequeñas transacciones de carácter económico, existe también un tipo de turismo alternativo que se considera como una herramienta útil para contribuir a la mejora de los países necesitados.

El concepto de turismo alternativo se desglosa en diferentes formas de turismo, entre las cuales destacamos:

- turismo sostenible: se propone optimizar los recursos del ambiente, conservando la biodiversidad; respetar la autenticidad sociocultural de la comunidad receptora; asegurar actividades económicas a largo plazo para reducir la pobreza; asegurar a los turistas una experiencia significativa (http://www.unep.fr/scp/tourism/ sustain/);

- ecoturismo: se trata de un viaje responsable realizado en áreas naturales con el objetivo de respetar el ambiente y contribuir al bienestar de las poblaciones locales (Epler Wood, 2002);

- turismo responsable: reconoce la centralidad de la comunidad local y su derecho a ser protagonista en el desarrollo turístico sostenible y socialmente responsable del territorio; además, fomenta una interacción positiva entre industria turística, viajeros y comunidades receptoras (Canestrini, 2004);

- turismo comunitario: se compone de experiencias turísticas integradas al medio rural y desarrolladas por los pobladores locales en beneficio de su propia comunidad. Se distingue por su dimensión humana y cultural, orientada a favorecer relaciones interculturales con los visitantes (Ruiz et al., 2008);

- turismo solidario: es una actividad económica en la que los procesos de desarrollo se realizan esencialmente en beneficio de las poblaciones directamente afectadas y ubicadas en países emergentes; además, minimiza el impacto sobre el entorno, tratando de conservar el patrimonio local, las culturas, las tradiciones, el medio ambiente, etc., y fortalece las sociedades locales, gracias a dinámicas económicas autónomas. Todo esto supone una relación muy estrecha entre el turista y los miembros de la comunidad local, ya que no se trata de un acto puramente económico, sino que el turista participará plenamente en las actividades cotidianas del pueblo viviendo con la población y conociendo sus costumbres y tradiciones (López-Guzmán Guzmán / Millán Vázquez de la Torre / Melián Navarro, 2007).

Las fronteras entre estos conceptos son muy resbaladizos, ya que todos ellos comparten el principio de un turismo centrado en el desarrollo y en el respeto de las comunidades locales, que aboga por la comprensión de los demás, así como del medioambiente que los rodea (LópezGuzmán Guzmán / Millán Vázquez de la Torre / Melián Navarro, 2007). Según esta visión, el turismo no es solo una experiencia lúdica, sino una oportunidad de confron- tación con culturas diferentes, en el signo del respeto recíproco (Albanese, 2007: 9).

\section{Buscamundos. Viajes por la vida}

Esta visión ética y solidaria del viaje es el ingrediente principal del programa televisivo Buscamundos. Viajes por la vida, que se transmitió en España, en La 2, desde el 30 de septiembre hasta el 30 de diciembre de 2011. En las 14 entregas, Miguel Romero, subdirector y presentador del programa, acompañado por diferentes copresentadoras (como la periodista Érika Reija y la actriz Lluvia Rojo), visitó Camboya, Kenia, Somalia, Buenos Aires y Etiopía, entre otros destinos. Si nos fijamos en el título de la mayoría de las entregas (New York. La capital del mundo, cap. 2 y New York. Ciudad oculta, cap. 3; Hong Kong. Ciudad con dos almas, cap. 6; Kenia y Somalia. Placer y dolor de África (cap. 7); y Buenos Aires. Ciudad invisible, cap. 9), nos percatamos de que el objetivo del programa es revelar las condiciones de vida de los países y su fisonomía menos conocida, sin escatimar los aspectos más desagradables, oponiéndose, por lo tanto, al lenguaje 'euforizante' que suele caracterizar la promoción turística (Dann, 1996).

Buscamundos pertenece a un género híbrido en el que se cruzan rasgos del documental y del reportaje de viaje. El programa ofrece un tema atemporal, no vinculado a la actualidad periodística, y la música de fondo proviene exclusivamente de los escenarios mostrados, es decir, se trata de un elemento diegético y no creativo o estético, elegido a posteriori, como ocurre con el documental (Gordillo, 1999: 47). No siempre se mantiene la neutralidad narrativa típica del enfoque documentalista, sino que a veces se adopta un tono más subjetivo, propio del reportaje, con el objetivo de acercarse a la sensibilidad del destinatario. Asimismo, la utilización de entrevistas es otro recurso propio de la libertad formal del reportaje (Gordillo, 2009: 131); de hecho, los presentadores se mueven entre la gente y realizan entrevistas a personajes significativos de cada país, como los actores Ricardo Darín o Federico Luppi; los humoristas Les Luthiers y Forges; el escritor Eduardo Galeano; y personajes políticos, como el presidente de Haití, Michel Joseph Martelly, o el eurodiputado Juan Fernando López Aguilar; además, se concede un espacio a los habitantes mismos (artesanos, taxistas, etc.). $\mathrm{Su}$ inclusión supone la ruptura del orden de los hechos e introduce una interpelación directa al espectador, puesto que estos personajes se dirigen al público, invitándolo a viajar a Haití.

El formato del programa prevé un narrador invisible, extradiegético, una voz en off, que relata las diferentes etapas del itinerario del viaje, y describe, por ejemplo, la condición de Haití, sus costumbres y sus tradiciones, y da informaciones prácticas acerca de los alojamientos, los medios de transporte, etc. Los presentadores, Miguel Romero con su compañera de aventura, mientras tanto, visitan los lugares, entran en contacto con la gente, observan, pero casi nunca se escucha su voz. Su función es funda- 
mentalmente acompañar al público en la realización del itinerario, recoger los testimonios de la gente, para que la visión de la localidad resulte lo más auténtica posible. Su actuación, así como su lenguaje, como veremos más adelante, parece libre de cualquier imposición del guión televisivo.

\section{Análisis del primer capítulo: Haití. Vacaciones en el infierno}

Este trabajo se configura como un estudio exploratorio de la comunicación turística a través del canal televisivo, con especial referencia a un tipo específico de turismo, el solidario. Para ello, me centraré en la primera entrega del programa Buscamundos, dedicada a Haití, que se emitió el 30 de septiembre de 2011, de 55’ de duración. A partir del material recogido y transcrito, me propongo analizar, mediante una metodología de tipo cualitativo, las estrategias comunicativas empleadas para perfilar el rostro de este devastado país y para convencer al público de la necesidad de considerarlo como un posible destino turístico, con el objetivo de evaluar si existen recursos discursivos y léxicos peculiares del turismo solidario.

En palabras del humorista Forges, Haití es "uno de los lugares más indicados para hacer turismo solidario", puesto que, desde que fue sacudido por un seísmo de magnitud 7 el 12 de enero de 2010, se han agudizado los ya graves problemas de este país. Desde entonces, los turistas han desaparecido, y con ellos se han desvanecido miles de puestos de trabajo, lo que ha supuesto un agravamiento para la reconstrucción del país. Hoy sus únicos visitantes son los cooperantes de organizaciones internacionales, que trabajan en tareas de ayuda humanitaria.

Si el turismo se concibe como una respuesta al estrés (Santana, 1997: 30), Haití representa justo lo contrario, como atestigua el título de este capítulo del programa, $\mathrm{Va}$ caciones en el infierno. Este oxímoron, que asocia el placer de las vacaciones a la tragedia, se contrapone netamente a las expresiones que se suelen emplear en la comunicación turística para promover la imagen de los destinos, centradas en los polos semánticos de lo pintoresco y lo grandioso, y elaboradas a partir de una serie de fundamentos, entre los cuales destacamos: evocación de emociones; presentación del entorno como una obra de arte; exaltación de la posición privilegiada; referencia al paraíso perdido; exposición épica de las características; énfasis en los vectores propios de la comodidad, etc. (Santana, 1997: 65).

Por otra parte, ya el título Vacaciones en el infierno evoca el turismo macabro (dark tourism), es decir, aquella forma de turismo que hace hincapié en la fascinación por la muerte y por la tragedia humana, a pesar de que estas no sean las intenciones de sus promotores (Lennon / Foley, 2000) ${ }^{1}$.

\section{Contenidos y polifonía}

El programa se configura como un espacio polifónico en el que se van mezclando diferentes voces: la del narra- dor en off, que es la voz principal del programa; las de los presentadores - los narradores intradiegéticos, implicados en los hechos relatados al ser los actores del viaje -, y las voces de los entrevistados.

Esta polifonía y el hecho de que la distribución de los contenidos se ajuste a las diferentes etapas del itinerario realizado determinan una progresión temática irregular con varios saltos. En efecto, se registra una fragmentación de las informaciones: los datos más prácticos se alternan con la descripción y la narración de la voz en off, sin olvidar el papel informativo de las imágenes.

En el capítulo examinado, Miguel y Érika recorren las calles llenas de escombros y cascotes de Puerto Príncipe y Léogane, o pasean por los mercados y los asentamientos precarios donde viven miles de personas. Asimismo, la pareja visita playas idílicas que han quedado huérfanas de gente, hoteles llenos de 'magia' y 'encanto' pero vacíos, y la zona de Pétionville en la que vive gente pudiente que compra en tiendas lujosas. Además, el programa enseña al público cómo viven los haitianos y sus costumbres y tradiciones: se hace referencia a los evangelistas que rezan e imploran la ayuda divina, a los ritos vudú, principal seña de identidad nacional, a la creencia en los zombis y a las supersticiones de esta población; se valorizan el arte y la artesanía, que denotan la riqueza surgida del mestizaje de culturas y sensibilidades diferentes. Se alude a la comida haitiana (la langosta, el plátano frito, etc.) y a la música; y, por último, se menciona el clima, a raíz de un chaparrón que cayó una tarde.

Por otra parte, se presentan algunos de los proyectos humanitarios que se están desarrollando en Haití, a través de breves entrevistas con los responsables. Intervienen también Fran Sevilla, corresponsal de RTVE y gran conocedor de la realidad haitiana, y el presidente de la República de Haití, que espera que los turistas vuelvan a esta zona, que según él es "maravillosa". A veces, estos encuentros parecen casuales: al oír hablar en español en el mercado o en el bar, los cooperantes humanitarios se dirigen con fingida naturalidad a los presentadores de Buscamundos.

Por último, se proporcionan algunas informaciones prácticas sobre precios de hoteles, restaurantes, medios de transporte, etc., que van apareciendo de forma esquemática en rótulos rojos en la pantalla y que, solo raras veces, se dan a través de la voz en off.

Las estampas de los distintos escenarios poseen un alto valor emocional, que contribuye a alcanzar la finalidad persuasiva del programa. La totalidad del capítulo está rodada en días nublados y grises, de acuerdo con la desolación general que se respira en Haití; incluso las grabaciones en la playa resultan poco atractivas por el mal tiempo. Tampoco se escatiman los primeros planos de las personas, sobre todo de niños, y los encuadres de las condiciones insalubres en las que vive la población haitiana, con el evidente propósito de enternecer al público. 
El lenguaje de los protagonistas: la voz en off y la voz de los presentadores

El capítulo tiene como fondo la voz de Toni Garrido², que describe la ciudad, narra su historia, y sigue el recorrido de los presentadores, desde Puerto Príncipe hasta Cap Haitien, pasando por Pétionville, Léogane y Jacmel.

La estrecha relación entre el audio y el vídeo queda patente sobre todo en las partes descriptivas del programa, en las que los deícticos espaciales remiten directamente al escenario descrito:

Graham Green situó aquí [en una posada muy famosa] su novela [...]

Allí mismo en el corazón de Puerto Príncipe habíamos quedado [...]

Aquí [en el campo de refugiados de Aviation] se aprovecha todo, aparatos averiados, ropa y calzados viejos $[\ldots]$

Con la descripción se intenta, por un lado, trasladar los estímulos sensoriales recibidos durante el viaje a un sistema de signos lingüísticos (Canals, 2010: 50) y, por otro, recalcar con las palabras los escenarios de miseria humana del país. Toni Garrido inserta en el discurso numerosos argumentos emocionales (pathos), que se apoyan en el sacudimiento de los sentimientos del receptor (López Eire, 1998: 29). El lenguaje que utiliza, sobre todo en la primera y en la última parte, se aleja de los rasgos que normalmente caracterizan los textos turísticos. De hecho, el léxico, en lugar de enaltecer las cualidades de Haití, se configura como una apología generalizada de su situación de dificultad y de desamparo y adquiere un tono dramático. Así pues, encontramos sustantivos y adjetivos que reposan en el fuerte impacto que ejercen la pobreza y el estado de desgracia en el que se halla Haití; a lo largo del programa, se oyen con cierta frecuencia palabras como: miserias, pobreza, desheredados, desplazados, desamparado, etc., incluso en expresiones con valor metafórico e hiperbólico o acompañadas por otros adjetivos o adverbios con valor intensificador:

Los extranjeros dejaron de llegar a Haití, los esperan en balde los artesanos, los hosteleros, miles de gentes empobrecidas [...]

Centenares de desplazados continúan sin hogar.

[...] miserias que horrorizan a los turistas.

[...] país lastrado por una profunda pobreza que oculta sus atractivos $[\ldots]$

[...] miserable hormigueo de Puerto Príncipe [...]

[...] legión de desamparados que nunca tuvieron nada y lo han perdido todo.

La tragedia infinita de su empobrecimiento histórico ahondado por el terremoto.

Un país empobrecido y devastado por un terremoto cuyas miserias horrorizan a sus visitantes.
[...] situación general de pobreza crónica [...]

La pobreza como mal endémico de Haití está siempre presente.

Siguiendo la metáfora dantesca del infierno, a la que se recurre en el subtítulo del programa, se habla de las ollas del infierno para referirse a un barrio:

Aunque sea muy difícil de establecer cuál es la peor olla del infierno, dicen que el barrio más inhumano de Puerto Príncipe es Cité Soleil, aquí malviven más de 200.000 personas.

Las palabras sufrimiento, dolor, herida, malvivir, por una parte, y ruinas, cascote, desolación, derrumbar, por otra, configuran el campo semántico del dolor y de la destrucción, que empeoraron a raíz del terremoto:

Las ruinas del palacio presidencial que se desplomó como un castillo de naipes [...]

Algunas casas del barrio amenazan con derrumbarse $[\ldots]$

Las tiendas de desplazados cubren las calles con un manto de dolor extendido sobre una antigua y profunda pobreza.

Toda la ciudad es un riesgo.

[...] ciudad gravemente herida [...]

La vida sigue entre la desolación y los escombros.

Asimismo, se recurre al campo semántico del abandono y de la precariedad, con expresiones como abandono, aguas negras, falta de higiene, desastre, cloacas, falta de servicios mínimos, basura:

Miles de niños crecen con las aguas negras de una inmensa cloaca faltos de los mínimos servicios sanitarios.

La existencia entre basuras de miles de desheredados es la cara insoportable de Haití.

[...] niños crecen entre desperdicios [...]

Otras palabras pertenecen al campo semántico de la inseguridad y de la desesperanza:

[...] ambiente de extrema violencia.

[...] la delincuencia como única salida para sobrevivir en una absoluta marginación social.

Pasear en la oscuridad supone un riesgo inútil. Por las noches es muy raro cruzarse con un extranjero.

[.... desesperanza que aflige a la capital haitiana.

El futuro está condicionado por las carencias, insalubridad e inseguridad.

Haití se tilda de infierno y de destino maldito.

También se subraya que el país está abandonado tanto por el gobierno como por la policía:

[...] Quiebra absoluta del gobierno haitiano con la 
administración pública sepultada bajo montañas de cascotes.

Los agentes irrumpen de vez en cuando, efectúan algunas detenciones y se marchan.

La misma denuncia se encuentra en la letra de la canción de un haitiano ciego que subraya la poca ayuda que las víctimas del seísmo han recibido por parte de los malos gobernantes y, por consiguiente, no le queda otra posibilidad que esperar que vuelvan los turistas a los que pedir limosna:

Los dirigentes de mi país son malos, no nos ayudan a nosotros, los pobres. Es por eso que nosotros, los pobres, les pedimos limosna a quienes vienen a Haití. Bienvenidos a mi país.

Por otra parte, se destacan la gran humanidad y la fuerza de la población, que siempre demuestra una gran alegría:

[...] inolvidable sobre todo por la cordialidad y el buen humor que siempre demuestran los más humildes.

Nunca faltan unas risas que compartir con las visitas. Nos conmovieron las miradas y las sonrisas de los más humildes algo que hace imposible que nos olvidemos de Haití.

En Haití, existen también algunos rincones y atractivos que hacen de contrapeso a la miseria y a la pobreza. El salto argumentativo está marcado por conectores contraargumentativos, como pero, sin embargo:

Los edificios oficiales reducidos a cascotes y el drama común a millares de damnificados ofrecen la primera estampa de una capital arrasada. Pero no tardaremos en descubrir que Haití tiene mucho más que ofrecer a sus viajeros.

Sin embargo Haití tiene su encanto.

o por expresiones como: lejos de...; el paisaje cambió radicalmente; el contraste con...; de vuelta a nuestro mundo de privilegiados, regresamos a, que marcan el paso de la estampa de desasosiego a la de paz o, al revés, de la tranquilidad al infierno:

Lejos del miserable hormigueo de Puerto Príncipe el paisaje es muy diferente. Pétionville es el barrio de los ricos donde se guarecen los privilegiados de la injusta sociedad haitiana.

Salimos del agobio de Puerto Príncipe en busca de las playas [...] Al cabo de una hora y media de carretera el paisaje cambió radicalmente, parecía un país distinto, libre de la desesperanza que aflige la capital haitiana. Regresamos al infierno social de Puerto Príncipe.

De vuelta a nuestro mundo de privilegiados en el ambiente confortable de [...]

En Pétionville están también los hoteles más lujosos
[...] islas de bienestar en un mar de miserias [...] garantizan un ambiente de lujo aislado de la realidad circundante.

El tono se hace más alentador cuando se describen y se destacan las bellezas de las playas, de los monumentos históricos de la República haitiana. En este caso, se explotan las típicas estrategias de la promoción turística (Mapelli, 2008) y, en particular, la anteposición de adjetivos con valor connotativo:

En pleno centro de Puerto Príncipe se alza uno de los hoteles más fascinantes del mundo.

Las lujosas galerías comerciales sobreviven gracias a una clientela formada por los cooperantes [...]

En Pétionville están también los hoteles más lujosos.

En Jacmel hay muchos hoteles con encanto [...] habitaciones acogedoras.

Decidimos explorar las magníficas playas [...] arenas limpias [...] forman el paisaje soñado del Caribe.

Permite disfrutar de espléndidas vistas aéreas.

Lugar ideal para unas vacaciones.

La voz en off subraya más de una vez los rasgos contradictorios del panorama que se describe:

El contraste con el abandono, las basuras y la tensión de la capital supone una terapia de duchas frías y calientes para templar el ánimo de los viajeros que descubrimos lo que raramente ven los turistas.

Una pequeña locura más en el ambiente de contradicciones que estaban viviendo.

Otro aspecto reseñable es el valor argumentativo de las cifras o de los términos que de algún modo contienen la idea de 'número muy elevado'. Los datos concretos, calificados de "indignantes y conmovedores" por el narrador, tienen un gran impacto en el público:

4 de 10 niños padecen malnutrición y el 6\% no llega a superar el primer año de vida [...]

Miles de damnificados [...

La mitad de la población sobrevive con menos de un euro diario y solo la tercera parte dispone de agua potable.

El terremoto causó decenas de miles de muertos.

300.000 damnificados perdieron sus hogares.

El $80 \%$ de la población vivía ya con menos de lo imprescindible.

Ni siquiera se sabe dónde tirar los miles de toneladas de cascotes que quedan por recoger.

[...] islas de bienestar en un mar de miserias [...]

[...] legión de desamparados [...]

En el relato de las diferentes etapas del viaje, Toni Garrido emplea casi siempre un nosotros participativo, que incluye a Miguel y Érika. Cabe recordar que las formas participativas son habituales en los textos turísticos di- 
rigidos al público, sobre todo en los itinerarios y en los programas de viaje, en combinación con verbos de percepción física, mental y de movimiento (Calvi, 2006; Mapelli, 2011). Esta personalización del discurso dinamiza las secuencias descriptivas y tiene también la función de involucrar al espectador en el discurso, proyectándolo hacia un viaje posible:

El paseo por la ciudad nos permitiría [...]

Salimos del agobio de Puerto Príncipe en busca de las playas $[\ldots]$

Nosotros escogimos el Florita, un edificio histórico [...] Regresamos al infierno social de Puerto Príncipe [...]

Conocimos a la directora de UNICEF España [...]

Decidimos madrugar y viajar en avión cansados ya de carreteras [...]

La voz en off solo en escasas ocasiones se refiere a Miguel y a Érika excluyéndose del grupo:

[...] a pesar de la lluvia, Miguel y Érika no desistieron de bañarse.

El papa del vudú haitiano mantuvo con Miguel y Érika unos minutos de interesante charla.

Se establece, además, un diálogo entre los presentadores y la voz extradiégetica, como en el siguiente ejemplo, en el que Érika ratifica con una exclamación lo que acaba de afirmar el narrador:

Voz en off: Llegamos al atardecer.

Érika: ¡Por fin estamos en Puerto Príncipe!

Por lo que se refiere a Miguel y a Érika, cabe señalar que son figuras de segundo plano, a pesar de encontrarse in situ. Se recogen solo algunos comentarios suyos, a veces incluso banales; el tono de sus intervenciones es coloquial, como cuando la periodista entra en la habitación de una posada de Puerto Príncipe y dice:

\section{É: Está muy bien... no hay aire acondiciona(d)o.}

o cuando se divierten probándose las máscaras de papel mâché en un mercado de artesanía:

M.: Estás muy guapa.

É.: Estoy muy guapa, gracias, a ver tú.

M.: Mira esta se parece a mí, ¿no?

É.: A ver... pruebátela, mucho más guapo.

o también cuando están en la playa:

M.: Un bañito en la playa y una langosta... menudo lujo.

É.: ¡Venteeee!

M.: iAl agua!

M.: ¡El agua esta buenísima!
En algunas intervenciones, los dos presentadores completan la exposición de Toni con otras informaciones:

M.: El castillo lo construyeron después de la independencia para defenderse porque tenían miedo a que volvieran los franceses.

É.: Estamos en Cité Soleil, uno de los barrios más peligrosos de todo Haití.

M.: Es una de las zonas con más miseria de América,

o con consejos:

M.: Vamos a dar un paseo con muchísimo cuidado y rápidamente.

É.: Se recomienda no salir por la noche [...] porque dicen que es peligroso [...] no está nada mal darse una vuelta para ver lo que hay pero con los ojos abiertos.

El narrador y los presentadores coinciden en un aspecto: ambos reiteran la idea de que viajar a Haití es conveniente desde el punto de vista económico, teniendo en cuenta que el bajo coste ofrece un gran atractivo (Cetti Serbelloni, 2007: 28):

É.: Una habitación acogedora por tan solo 45 euros.

M.: Cuatro estampas y una figura 100 dólares, no está mal.

Voz en off: Viajar a Haití no es nada caro.

\section{Buscamundos y la Web}

En conformidad con las actuales tendencias para la difusión de informaciones y para interaccionar con el usuario, el programa tiene también una página web general (http://www.rtve.es/television/buscamundos/) y otra para cada entrega, más detallada, sobre el destino presentado; asimismo, presenta una página en Facebook. Dichas páginas se configuran como un macrogénero (Calvi, 2010), ya que engloban una amplia variedad de materiales, no solo textuales, sino también audiovisuales e icónicos, con su correspondiente articulación genérica (Calvi, 2011: 21).

Por lo que se refiere a Haití, en la página de Buscamundos de RTVE (http://www.rtve.es/television/buscamundos/haiti/), además del vídeo del capítulo retransmitido en la televisión, se encuentran documentos de diferentes tipos: vídeos inéditos, materiales de audio y noticias, a veces extraídos de otros programas o de los telediarios de RTVE. Aparece también una parte interactiva en la que los usuarios pueden cargar sus fotos. Asimismo, se recoge un mapa del itinerario realizado y algunas informaciones prácticas. Es interesante detenerse en el subtítulo del apartado Blog, Ligeros de equipaje, una cita machadiana que remite, una vez más, al viajero independiente que no se desplaza en busca de bienes materiales sino de vivencias y relaciones con otras culturas ${ }^{3}$. Sin embargo la interactividad que proporciona el medio no está muy explotada. De hecho, es reducido el número de los comentarios 
que ha dejado la audiencia a los blogs y a los vídeos.

Buscamundos está también en Facebook. En el "muro" el moderador anuncia el viaje y el público, después del visionado del programa, puede dejar sus impresiones. Cada post tiene una media de 40 "Me gusta", pero los comentarios son casi inexistentes: van desde los cuatro del viaje a Hong Kong hasta los 16 del viaje a Buenos Aires. En el post dedicado a Haití, se cuentan solo cinco comentarios muy breves, en los que los "amigos" dan las gracias a los presentadores y expresan una opinión positiva sobre este nuevo formato.

Si tenemos en cuenta que, en la actualidad, las redes sociales son las herramientas más recurridas para informarse sobre un destino turístico (Domínguez Vila / Araújo Vila 2012), la escasa participación de los usuarios en las páginas dedicadas al programa parece indicar un impacto todavía bastante limitado.

\section{Conclusiones}

La primera entrega de Buscamundos se fundamenta en la idea de que viajar a Haití es muy importante por razones humanitarias y, en cierto sentido, "antiturísticas". Para perfilar la condición de Haití y convencer a la audiencia a emprender este tipo de turismo solidario y consciente, se recurre a una serie de estrategias lingüísticas y visuales. Tanto el texto oral como los elementos visuales muestran las luces y las sombras de este destino; se enseñan, por un lado, las bellezas del lugar (como el mar, las playas, los hoteles acogedores, las sonrisas de la gente), pero, por otro, se recurre a los campos semánticos de la miseria, de la inseguridad, del sufrimiento, etc., y a imágenes que, desde el comienzo hasta el final, no escatiman las estampas de las víctimas más desvalidas, para conmover al público. Los argumentos emocionales utilizados son eficaces, ya que tanto el lenguaje como las imágenes hacen hincapié en la pietas para sensibilizar a la audiencia y estimularla a una acción concreta, de acuerdo con la filosofía del programa. En este diseño, se pretende, por lo tanto, que el viajero conozca la back region (MacCannell, 1973), es decir, el lugar no turístico de la autenticidad, modificando su mirada, o gaze (Urry, 1990) a través de la interacción con la población local. Creemos, sin embargo, que la excesiva insistencia en el "espectáculo" ofrecido por la tragedia podría estimular la modalidad más oscura y macabra del turismo, el llamado dark tourism.

Desde nuestro punto de vista, cabe señalar las repercusiones lingüísticas de la reciente difusión de nuevas modalidades de turismo alternativo, que rompen con los rasgos prototípicos del discurso turístico (Calvi, 2006), acentuando el peso de los elementos disfóricos. Por otra parte, la polifonía que caracteriza el capítulo estudiado es una señal de la preferencia por formas comunicativas más abiertas y dialógicas, que acompañan el desarrollo de nuevas formas de turismo.

\section{Bibliografía}

\section{Albanese, Antonietta}

2007 "Presentazione". En Albanese, A. / Cristini, C. (Eds.), Psicologia del turismo: Prospettive future (pp. 7-9). Milano: FrancoAngeli.

Calvi, Maria Vittoria

2006 Lengua y comunicación en el español del turismo. Madrid: Arco/Libros.

Calvi, Maria Vittoria

2010 "Los géneros discursivos en la lengua del turismo: una propuesta de clasificación”. Ibérica, 19: 9-32.

Calvi,Maria Vittoria

2011 "Pautas de análisis para los géneros del turismo". En Calvi, M. V. / Mapelli, G. (Eds.), La lengua del turismo. Géneros discursivos y terminología (pp. 19-45). Bern: Peter Lang.

Canals, Jordi

2010 "Describir el viaje". En Canals, J. / Liverani, E. (Eds.), Viajar con la palabra (pp. 49-66). Milano: FrancoAngeli.

Canestrini, Duccio

2004 Andare a quel paese. Milano: Feltrinelli.

Cetti Serbelloni, Francesco

2007 "La formazione del turista: prospettive future?". En Albanese, A. / Cristini, C. (Eds.), Psicologia del turismo: Prospettive future (pp. 25-30). Milano: FrancoAngeli.

Dann, Graham

1996 The language of tourism. A sociolinguistic perspective. Oxon UK: CAB International.

Domínguez Vila, Trinidad / Araújo Vila, Noelia

2012 "El fenómeno 2.0 en el sector turístico. El caso de Madrid 2.0". Pasos. Revista de turismo y patrimonio cultural,10/3: 225-237.

Epler Wood, Megan

2002 Ecotourism: principles, practices and policies for sustainability. Minnesota: UNEP.

Gordillo, Inmaculada

1999 Narrativa y televisión. Madrid: MAD.

Gordillo, Inmaculada

2009 Manual de narrativa televisiva. Madrid: Síntesis.

Lennon, John / Foley, Malcom

2000 Dark tourism: the attraction of death and disaster. London: Continuum.

López Eire, Antonio

1998 La retórica en la publicidad. Madrid: Arco/Libros.

López-Guzmán Guzmán, Tomás / Millán Vázquez de la Torre, Genoveva / Melián Navarro, Amparo

2007 "Turismo solidario. Una perspectiva desde la Unión Europea”. Gestión turística, 8: 85-104.

Mapelli, Giovanna

2008 "Las marcas de metadiscurso interpersonal de la sección 'turismo' de los sitios web de los ayuntamientos". En Calvi, M. V. / Mapelli, G. /Santos López, J. (Eds.), Lingue, culture, economia: comunicazione e pratiche 
discorsive (pp. 173-190). Milano: FrancoAngeli.

Mapelli, Giovanna / Piccioni, Sara

2011 "Taxonomía de los textos turísticos: factores lingüísticos y factores contextuales". En Calvi, M. V. / Mapelli, G. (Eds.), La lengua del turismo. Géneros discursivos y terminología (pp. 47-73). Bern: Peter Lang.

MacCannell, Dean

1973 "Staged Authenticity: Arrangements of Social Space in Tourist Settings". American Journal of Sociology, 79/3: 589-603.

Ruiz, Esteban et al.

2008 "Turismo comunitario en Ecuador. Comprendiendo el community-based tourism desde la comunidad". Pasos. Revista de turismo y patrimonio cultural, 6/3: 399-418.

Santana, Agustín

1997 Antropología y turismo. ¿Nuevas hordas, viejas culturas? Barcelona: Ariel.

Urry, John

1990 The tourist gaze. Leisure and travel in contemporary societies. London: Sage.

\section{Notas}

1 Teatro de este tipo de turismo son por ejemplo Hiroshima, Aushwitz, Ground Zero, Chernobyl, etc.

2 Toni Garrido es locutor del programa radiofónico Asuntos propios.

3 Cabe recordar, a este respecto, que la última campaña de Turespaña, I need Spain, hace hincapié en este mismo concepto. En uno de los vídeos promocionales, en efecto, se oye la siguiente frase: "Cuantas menos cosas pongas en la maleta, más espacio queda para las vivencias". Véase el artículo de Mariottini en este mismo Especial.

Sometido a evaluación por pares anónimos 